\title{
Bergenin suppresses the growth of colorectal cancer cells by inhibiting PI3K/AKT/mTOR signaling pathway
}

\author{
Xucan Gao ${ }^{1,2}$, Yazhu Wang ${ }^{2}$, Jianzhuo Zhang ${ }^{2}$, Lifen Lin $^{2}$, Qi Yao ${ }^{2}$ and Guoan \\ Xiang $^{1 *}$ \\ ${ }^{1}$ Department of General Surgery, The Second People's Hospital of Guangdong Province. The Third Clinical Medical College, \\ Southern Medical University, Guangzhou 510515, ${ }^{2}$ Department of Coloproctological Surgery, Shenzhen People's Hospital, The \\ Second Clinical Medical College, Jinan University, Shenzhen 510000, Guangdong, China
}

*For correspondence: Email: guoan_66@163.com; Tel: +86-20-89168084

Sent for review: 7 May 2017

Revised accepted: 23 September 2017

\begin{abstract}
Purpose: To investigate anticancer effects of bergenin on human colorectal cancer cell lines. Methods: Human colorectal adenocarcinoma cell line HCT116 was treated with various concentrations of bergenin for 24 and $48 \mathrm{~h}$. Cell viability, apoptosis, cell cycle arrest and reactive oxygen species (ROS) level were analyzed by MTT, flow cytometry and fluorescent dye assays, respectively. DNA damage-associated protein expressions were analyzed by Western blotting.

Results: Bergenin significantly suppressed the viability of HCT116 cells. Moreover, bergenin induced cells to accumulate in G1 phase and resulted in DNA breaks in HCT116 cells. It also led to marked accumulation of intracellular reactive oxygen species (ROS), a breaker of DNA strand in HCT116 cells. Interestingly, bergenin inhibited PI3K/AKT/mTOR pathway.

Conclusion: Bergenin effectively suppresses the growth of colorectal adenocarcinoma by inducing generation of intracellular ROS, DNA damage and consequent G1 phase arrest via inhibition of PIJK/AKT/mTOR pathway.
\end{abstract}

Keywords: Bergenin, Colorectal cancer, DNA damage, Cell cycle arrest, PI3KJAKT/mTOR

Tropical Journal of Pharmaceutical Research is indexed by Science Citation Index (SciSearch), Scopus, International Pharmaceutical Abstract, Chemical Abstracts, Embase, Index Copernicus, EBSCO, African Index Medicus, JournalSeek, Journal Citation Reports/Science Edition, Directory of Open Access Journals (DOAJ), African Journal Online, Bioline International, Open-J-Gate and Pharmacy Abstracts

\section{INTRODUCTION}

Colorectal cancer (CRC) is the third most common cancer and the fourth most common cause of cancer-related death, with between one and two million new cases being diagnosed every year, and its incidence has been increasing year by year [1]. Modifiable risk factors for CRC relating to lifestyle include smoking, physical activity habits, overweight, obesity and alcohol consumption. Chemotherapy and surgery are the most common treatment for CRC [2]. With the development and application of a new generation of chemotherapy and molecular-targeted drugs, the effects of CRC treatment have improved, but are still unsatisfactory. In addition, the toxic side effects of chemotherapy drugs and the failure of chemotherapy due to drug resistance are some of the drawbacks of clinical treatment [3].

Bergenin, an active constituent of the herb of Bergenia purpurascens (Hook. f. et Thoms.) Engl. has been widely used as an active antiinflammatory ingredient, which can inhibit chronic bronchitis, and attenuates chronic gastritis clinically [4,5]. Moreover, studies have reported that bergenin has various bioactivities, such as hepatoprotective [6], neuroprotective [7] and antioxidant properties [8]. Despite bergenin being 
known for its multifaceted activities, the anticolorectal carcinoma activity has not been studied.

The present study was designed to explore its efficiency in inhibition of cell growth in human colorectal carcinoma cells. In view of the effects on the activation of PI3K/AKT/mTOR pathway, the underlying mechanisms of how bergenin increases DNA damage and cell cycle arrest were explored.

\section{EXPERIMENTAL}

\section{Chemicals and reagents}

Bergenin $\left(\mathrm{C}_{14} \mathrm{H}_{16} \mathrm{O}_{9}\right.$, MW: 328.27 , purity $\left.\geq 98 \%\right)$ was purchased from Sigma-Aldrich (St. Louis, $\mathrm{MO}$, USA). Bergenin was dissolved in dimethylsulfoxide (DMSO) as stock solution of $0.1 \mathrm{M}$, stored at $-20^{\circ} \mathrm{C}$, and freshly diluted with RPMI-1640 medium (Gibco, Carlsbad, CA, USA) to the final concentration used in the study. MTT [3-(4, 5-dimethylthiazol-2-yl)-2, 5-diphenytetrazoliumbromide] and $\mathrm{N}$-acetyl-I-cysteine (NAC) were obtained from Sigma-Aldrich. Antibodies against p-AKT (Ser473), total AKT, pmTOR (Ser2448), total mTOR and GAPDH were purchased from Bioworld Technology, Inc. (Louis Park, MN, USA). p-H2AX (Ser139), H2AX antibodies were purchased from EnoGene Biotech (Nanjing, China). Other chemical products used were of analytical grade.

\section{Cell culture}

Human colorectal adenocarcinoma HCT116 cell line was obtained from American Type Culture Collection (Bethesda, MD, USA). Cells were cultured in RPMI-1640 medium (Gibco), supplemented with $10 \%$ fetal bovine serum (Gibco), $100 \mathrm{U} / \mathrm{mL}$ benzyl penicillin and 100 $\mathrm{mg} / \mathrm{mL}$ streptomycin. Cells were cultured in a humidified environment with $5 \% \mathrm{CO}_{2}$ at $37^{\circ} \mathrm{C}$.

\section{Cell viability assay}

Cell viability was measured using the colorimetric MTT assay as described previously $[9,10]$. The cells were incubated overnight and then treated with various concentrations of bergenin, and incubated for 24 and $48 \mathrm{~h}$. Subsequently, $20 \mu \mathrm{L}$ of MTT solution $(5 \mathrm{mg} / \mathrm{mL})$ was added to each well. The plate was incubated at $37^{\circ} \mathrm{C}$ in a $5 \%$ $\mathrm{CO}_{2}$ atmosphere for $4 \mathrm{~h}$, the supernatants were removed and $150 \mu \mathrm{L} /$ well DMSO was added then placed in an orbital shaker for $5 \mathrm{~min}$, and the absorbance was recorded at $570 \mathrm{~nm}$ with a Model 1500 Multiskan spectrum microplate reader (Thermo, Waltham, MA, USA). Data were analyzed from three independent experiments and then normalized to the absorbance of the wells containing media only $(0 \%)$ and untreated cells $(100 \%)$.

\section{Apoptosis analysis}

HCT116 cells were treated with various concentrations of bergenin and were harvested by trypsinization and then washed twice with PBS. Cells were stained with Annexin V-FITC and $\mathrm{PI}$, and then analyzed with a FACSCalibur flow cytometer using Cell Quest software (BD Bioscience, San Jose, CA, USA). Results were analyzed using Flowjo 7.6 software (Treestar, Ashland, OR, USA).

\section{Cell cycle analysis}

HCT116 cells were treated with various concentrations of bergenin and were harvested by trypsinization, fixed with $70 \%$ ethanol and stored at $-20{ }^{\circ} \mathrm{C}$ for at least 1 day. Following fixation, cells were subjected to a PBS wash and then stained with DNA staining solution comprising $2.5 \mathrm{mg} / \mathrm{mL}$ propidium iodide $(\mathrm{PI})$ and $50 \mathrm{mg} / \mathrm{mL}$ RNaseA in PBS. Samples were incubated at $37^{\circ} \mathrm{C}$ for 30 min away from light and then analyzed on a FACSCabibur flow cytometer (BD Bioscience) [9]. Results were analyzed using Flowjo 7.6 software (Treestar).

\section{Western blotting}

Whole cell lysates from HCT116 cells were prepared by suspending cells in NP40 buffer. The equal concentration of protein lysate of all the samples was separated on $8 \%$ SDS-PAGE gel and further transferred to nitrocellulose membranes. The membranes were blocked with $5 \%$ nonfat milk for $2 \mathrm{~h}$, and incubated overnight at $4{ }^{\circ} \mathrm{C}$ with specific primary antibodies against p-AKT (Ser473), AKT, p-mTOR (Ser2448), mTOR, p-H2AX (Ser139), H2AX and GAPDH, and then incubated with IRDye-conjugated secondary antibody for $1 \mathrm{~h}$ at $37^{\circ} \mathrm{C}$. Detection was performed by the Odyssey Infrared Imaging System (LI-COR, Inc., Lincoln, MT, USA).

\section{Measurement of ROS level}

The production of cellular reactive oxygen species (ROS) was detected using fluorescent dye, 2, 7-dichlorofluoresceindiacetate (DCFHDA, Beyotime Institute of Biotechnology, China) as previously described [11]. In brief, HCT116 cells were pretreated with/without NAC for $2 \mathrm{~h}$ and then exposed to bergenin for $12 \mathrm{~h}$. Then cells were collected and incubated with $10 \mu \mathrm{M}$ DCFH-DA attenuated with serum-free medium 
for $30 \mathrm{~min}$ at $37^{\circ} \mathrm{C}$ in the dark. After washing with serum-free medium, ROS level was measured by intensity of the fluorescence produced on a Model 1500 Multiskan spectrum microplate reader (Thermo).

\section{Statistical analysis}

Data are presented as mean \pm SEM $(n=3)$. Data sets were performed using one-way analysis of variance (ANOVA) followed by Dunnett's test between control and experimental groups. $P<$ 0.05 was considered significant.

\section{RESULTS}

\section{Effect of bergenin on growth of human colon cancer cells}

At first, we examined the effect of bergenin at different concentrations on cell viability. As shown in Figure 1, after 24 and $48 \mathrm{~h}$ of treatment, bergenin markedly inhibited the cell growth in HCT116 cells in a concentrationdependent manner.

\section{Effect of bergenin on cell apoptosis in colon cancer cells}

We next evaluated apoptosis in HCT116 cells after treatment with 3,10 and $30 \mu \mathrm{M}$ bergenin for $24 \mathrm{~h}$, the percentage of total apoptosis cells were $2.53 \pm 0.51 \%, 5.21 \% \pm 0.93 \%, 8.56 \pm 1.02 \%$ and $14.87 \pm 1.35 \%$, respectively (Figure 2 ).

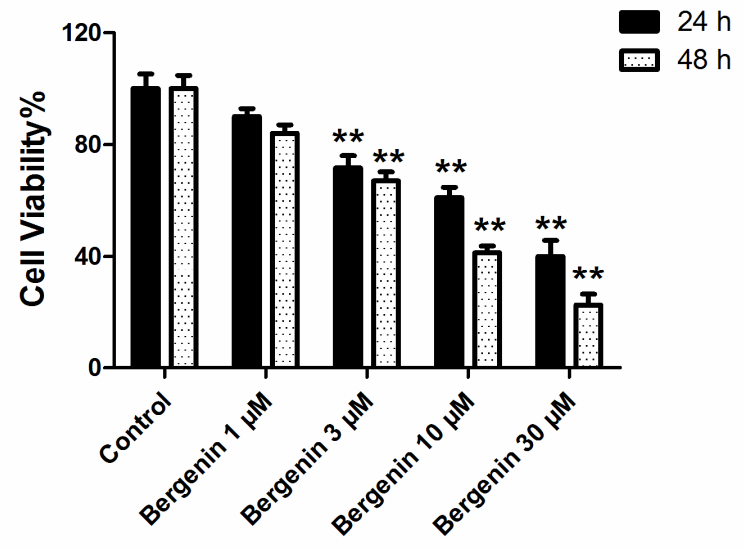

Figure 1: Effect of bergenin on the growth of human colon cancer cells. HCT116 cells were incubated with various concentrations of bergenin $(1,3,10,30 \mu \mathrm{M})$ for 24 and $48 \mathrm{~h}$, and cell viability was analyzed by MTT assay. Data were presented as means \pm SEM of three independent experiments; ${ }^{*} p<0.05,{ }^{* *} p<0.01$ vs control

\section{Effect of bergenin on cell cycle in colon cancer cells}

Because of the significant inhibitory effect on cell viability and growth, we estimated the effect of bergenin on the distribution of cells in the cell cycle. As shown in Figure 3 , bergenin $(3,10,30$ $\mu \mathrm{M})$ treatment led to an increase in the number of cells in the G1 phase with decreased percentage of cells in the S phase at $24 \mathrm{~h}$. The

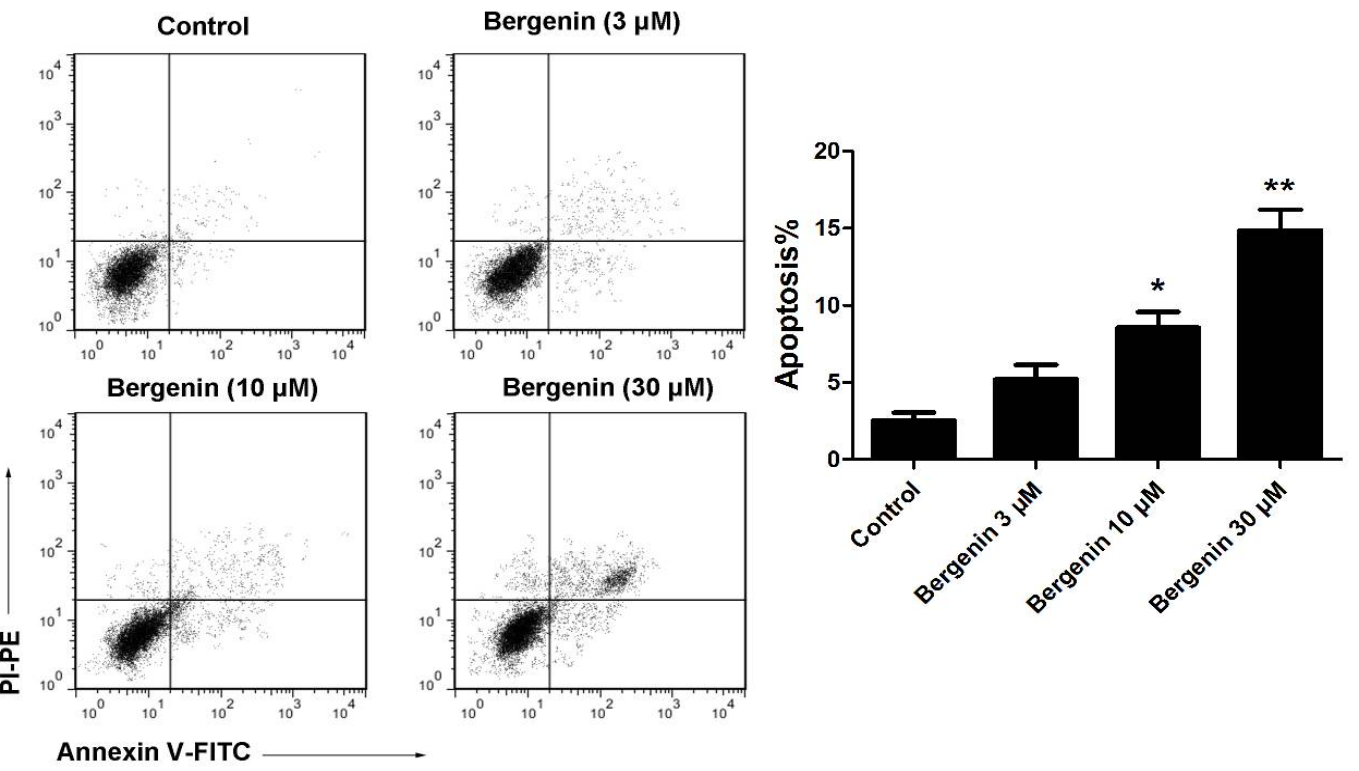

Figure 2: Effect of bergenin on cell apoptosis in colon cancer cells. HCT116 cells were incubated with various concentrations of bergenin $(3,10,30 \mu \mathrm{M})$ for $24 \mathrm{~h}$, and cell apoptosis was stained with Annexin V/PI followed by flow cytometry. The percentages of cells in apoptosis were represented. Data were presented as means \pm SEM of three independent experiments; ${ }^{*} p<0.05,{ }^{* *} p<0.01$ vs control 
data showed that the number of cells in the G1 phase was 1.5 -fold and 2-fold at 10 and $30 \mu \mathrm{M}$ at $24 \mathrm{~h}$, respectively.

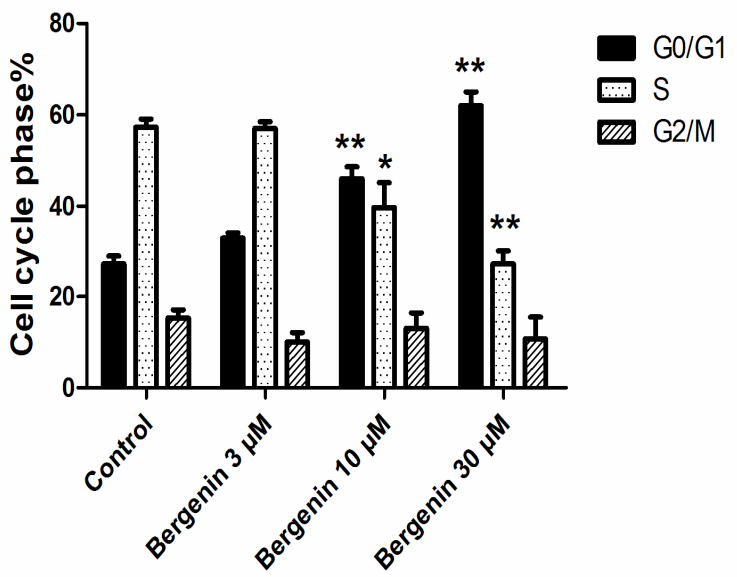

Figure 3: Effect of bergenin on the cell cycle in colon cancer cells. HCT116 cells were incubated with various concentrations of bergenin $(3,10,30 \mu \mathrm{M})$ for $24 \mathrm{~h}$, and the cell cycle was analyzed by flow cytometry after staining with propidium iodide. Cells in G0/G1, S and G2/M phases were quantified and presented. Data were presented as means \pm SEM of three independent experiments; ${ }^{*} p<0.05,{ }^{* *} p<0.01$ vs control

\section{Effect of bergenin on DNA damage}

We investigated the phosphorylation of histone variant H2AX at Ser139, an indicator of DNA break. As shown in Figure 4, bergenin markedly increased the level of phosphorylated H2AX at Ser139 in a concentration-dependent manner. The results indicated that bergenin might lead to DNA damage in HCT116 cells.

\section{Effect of bergenin on ROS level}

To investigate the effect of bergenin on ROS generation, we detected the levels of ROS in bergenin-treated cells. It was shown that bergenin $(10$ and $30 \mu \mathrm{M})$ treatment induced a substantial increase in ROS levels in HCT116 cells at $24 \mathrm{~h}$. In addition, NAC (a ROS scavenger) markedly decreased the accumulation of ROS induced by bergenin (Figure 5).

\section{Effect of bergenin on activation PI3K/AKT/ mTOR pathway}

The canonical PI3K/AKT/mTOR signaling pathway has emerged as a critical regulator pathway of cell proliferation [1].

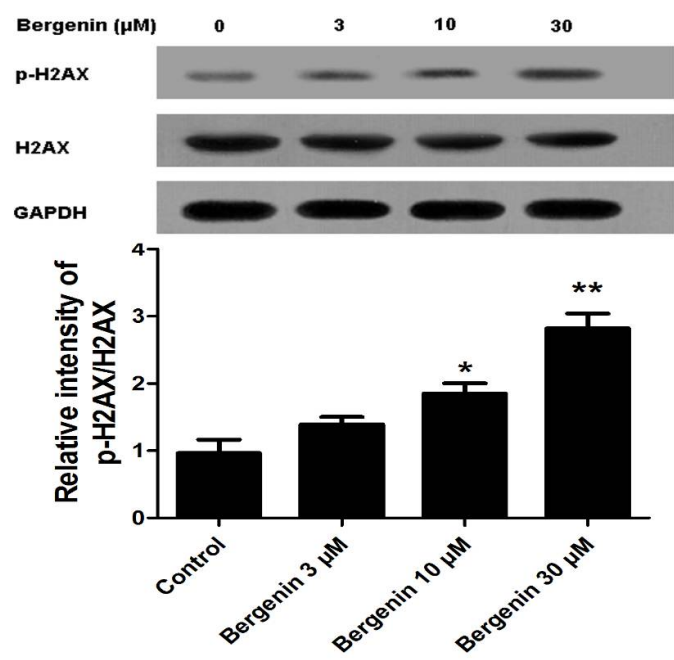

Figure 4: Effect of bergenin on DNA damage. HCT116 cells were incubated with various concentrations of bergenin $(3,10,30 \mu \mathrm{M})$ for $24 \mathrm{~h}$. Cell were harvested and lysed, and the levels of $\mathrm{p}-\mathrm{H} 2 \mathrm{AX}$, $\mathrm{H} 2 \mathrm{AX}$ and GAPDH were analyzed by immunoblotting. Densitometry analysis of immunoblotting was also shown. Data were presented as means \pm SEM of three independent experiments ${ }^{*} p<0.05,{ }^{* *} p<0.01$ vs control

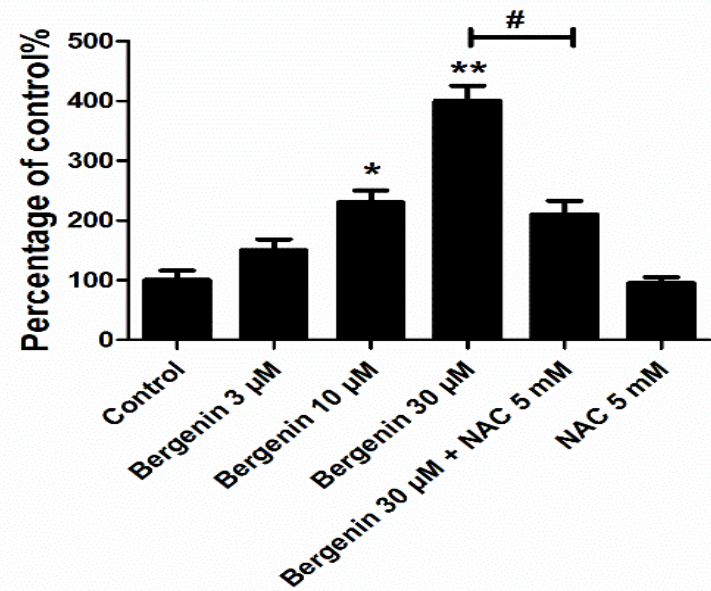

Figure 5: Effect of bergenin on ROS level. HCT116 cells were pretreated with/without NAC for $2 \mathrm{~h}$ and then exposed to various concentrations of bergenin ( 3 , $10,30 \mu \mathrm{M})$ for $12 \mathrm{~h}$. ROS level was tested with fluorescence probe DCFH2-DA. Data were presented as means \pm SEM of three independent experiments; ${ }^{*} p<0.05,{ }^{* *} p<0.01$ vs control. $\# p<0.05$ vs the indicated

Our former data showed that bergenin could down-regulate cell viability and growth, thus we tested the effect of bergenin on PI3K/AKT/mTOR signaling pathway. Western blot analysis showed that bergenin markedly decreased the phosphorylation levels of AKT and mTOR, while it had no significant effect on the total levels of AKT and mTOR in a concentration-dependent manner (Figure 6). 

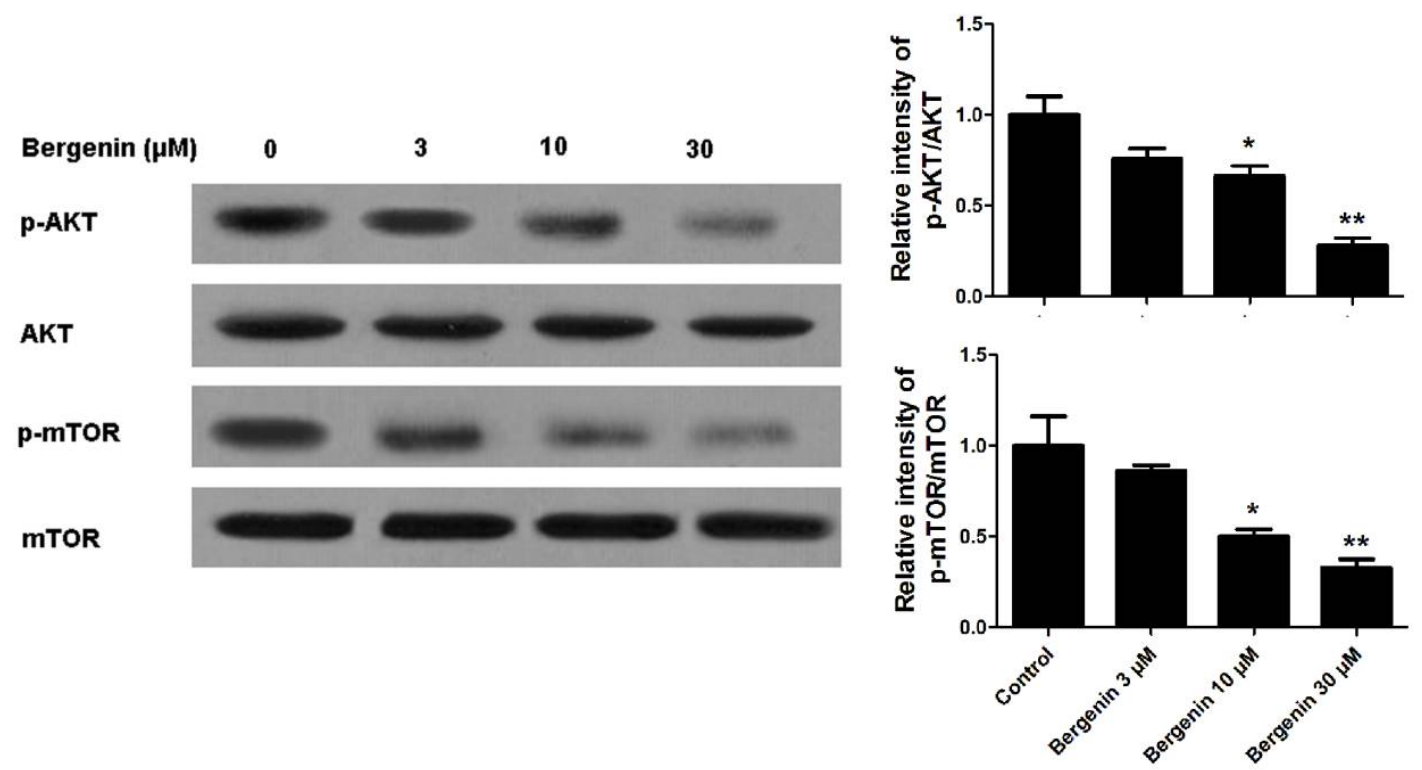

Figure 6: Effect of bergenin on the activation PI3K/AKT/mTOR pathway. HCT116 cells were incubated with various concentrations of bergenin $(3,10,30 \mu \mathrm{M})$ for $24 \mathrm{~h}$. Cell were harvested and lysed, and the levels of $p$ AKT, AKT, p-mTOR and mTOR were analyzed by immunoblotting. Densitometry analysis of immunoblotting was also shown. Data were presented as means \pm SEM of three independent experiments; ${ }^{*} p<0.05,{ }^{* *} p<0.01$ vs control

\section{DISCUSSION}

$\mathrm{CRC}$ is one of the most common causes of cancer mortality. Traditional Chinese medicines have been recognized as new source of anticancer drugs as well as new chemotherapy adjuvants that enhance efficacy and diminish side effects of chemotherapeutic agent. In this study, bergenin showed significant inhibitory effect on the growth of HCT116 cells. Bergenin induced ROS-mediated DNA damage, which resulted in $\mathrm{G} 1$ phase arrest and inhibited the activation of PI3K/AKT/mTOR pathway.

Bergenin could significantly inhibit HCT116 cell proliferation and growth in a concentration- and time-dependent manner, which demonstrated that bergenin was a potent cytotoxic compound. Cell cycle is the essential mechanism by which all cells reproduce. New links between alterations in the cell cycle regulatory machinery and tumorigenesis are being constantly reported and virtually all molecular species involved in regulating cell proliferation described in the literature have been related to malignant transformation [12]. Thus, we assumed that bergenin-induced cell growth inhibition was due to cell cycle arrest. We found that bergenin induced concentration-dependent $\mathrm{G} 1$ phase cell cycle arrest in HCT116 cells. In advanced CRC, cancer cells usually become resistant to apoptosis [13]. Thus, identification that bergenin that can induce apoptosis in CRC cells is highly desirable. The results showed bergenin treatment for $24 \mathrm{~h}$ in HCT116 cells led to an elevated percentage of apoptotic cells.

Many drugs in use disrupt genome integrity by causing DNA strand breaks, and consequently block cell proliferation mainly by suppressing factors that enable cells to proceed from one cell cycle phase to the next through checkpoints in the cell division cycle [14]. Then, we hypothesized that bergenin induced DNA damage, leading to G1 cell cycle arrest and apoptosis. The data showed that bergenin induced DNA damage in HCT116 cells in a concentration-dependent manner as confirmed by the increased level of p-H2AX (Ser139), the biomarker for DNA damage.

Accumulative data have indicated that induction of DNA damage by high levels of ROS can induce cell cycle arrest and apoptosis [15,16]. In normal cells, ROS are at low levels, which are important for the regulation of normal cell proliferation. However, cancer cells, which exhibit much higher levels of ROS close to the threshold of cytotoxicity, are susceptible to ROSgenerating agents $[17,18]$. In this study, bergenin led to a marked increase in ROS levels in HCT116 cells.

$\mathrm{PISK} / \mathrm{AKT} / \mathrm{mTOR}$ pathway is a particularly important pathway that has also been involved in regulating cell proliferation, cell cycle progression, apoptosis and morphogenesis in different organs [19,20]. Earlier work established 
that $\mathrm{PI} 3 \mathrm{~K} / \mathrm{AKT} / \mathrm{mTOR}$ signaling pathway plays a critical role in the development of human cancer including colorectal cancer [21]. Thus, to suppress the excessive activation of $\mathrm{PI} 3 \mathrm{~K} / \mathrm{AKT} / \mathrm{mTOR}$ signaling pathway is a key therapeutic method of colorectal cancer. Our data demonstrated that bergenin could markedly inhibit the levels of p-AKT and p-mTOR in HCT116 cells.

\section{CONCLUSION}

The findings demonstrate that cell growth inhibition and G1 phase arrest occur in colorectal carcinoma cells HCT116 exposed to bergenin. Bergenin efficiently induces the generation of intracellular ROS, DNA damage and consequent G1 phase arrest and inhibition of activation of $\mathrm{PISK} / \mathrm{AKT} / \mathrm{mTOR}$ pathway. These results provide new insights into the anti-cancer mechanisms of bergenin, which may be helpful in the potential development of bergenin into a promising therapeutic agent against colorectal carcinoma.

\section{DECLARATIONS}

\section{Acknowledgement}

The authors would like to thank The Second Clinical Medical College, Yangtze University, China for providing the necessary facilities for this work.

\section{Conflict of Interest}

No conflict of interest associated with this work.

\section{Contribution of Authors}

The authors declare that this work was done by the authors named in this article and all liabilities pertaining to claims relating to the content of this article will be borne by them.

\section{Open Access}

This is an Open Access article that uses a funding model which does not charge readers or their institutions for access and distributed under the terms of the Creative Commons Attribution License (http://creativecommons.org/licenses/by/ 4.0) and the Budapest Open Access Initiative (http://www.budapestopenaccessinitiative.org/rea d), which permit unrestricted use, distribution, and reproduction in any medium, provided the original work is properly credited.

\section{REFERENCES}

1. Marmol I, Sanchez-de-Diego C, Pradilla Dieste $A$, Cerrada E, Rodriguez Yoldi MJ. Colorectal Carcinoma: A General Overview and Future Perspectives in Colorectal Cancer. Int J Mol Sci 2017; 18.

2. Simon K. Colorectal cancer development and advances in screening. Clin Interv Aging 2016; 11: 967-976.

3. Peeters $M$, Oliner KS, Price TJ, Cervantes A, Sobrero AF, Ducreux M, Hotko $Y$, Andre T, Chan E, Lordick F, et al. Analysis of KRAS/NRAS Mutations in a Phase III Study of Panitumumab with FOLFIRI Compared with FOLFIRI Alone as Second-line Treatment for Metastatic Colorectal Cancer. Clin Cancer Res 2015; 21: 54695479.

4. Ren X, Ma S, Wang J, Tian S, Fu X, Liu X, Li Z, Zhao B, Wang $X$. Comparative effects of dexamethasone and bergenin on chronic bronchitis and their antiinflammatory mechanisms based on NMR metabolomics. Mol Biosyst 2016; 12: 1938-1947.

5. Yang $S$, Yu Z, Wang L, Yuan T, Wang X, Zhang X, Wang $J, L v Y, D u G$. The natural product bergenin ameliorates lipopolysaccharide-induced acute lung injury by inhibiting NF-kappaB activation. $J$ Ethnopharmacol 2017; 200: 147-155.

6. Lim HK, Kim HS, Choi HS, Choi J, Kim SH, Chang MJ. Effects of bergenin, the major constituent of Mallotus japonicus against D-galactosamine-induced hepatotoxicity in rats. Pharmacology 2001; 63: 71-75.

7. Takahashi $H$, Kosaka M, Watanabe $Y$, Nakade $K$, Fukuyama $Y$. Synthesis and neuroprotective activity of bergenin derivatives with antioxidant activity. Bioorg Med Chem 2003; 11: 1781-1788.

8. De Abreu HA, Aparecida Dos SLI, Souza GP, Pilo-Veloso $D$, Duarte $H A$, de CAAF. Antioxidant activity of (+)bergenin: a phytoconstituent isolated from the bark of Sacoglottis uchi Huber (Humireaceae). Org Biomol Chem 2008; 6: 2713-2718.

9. Zhao $P$, Chen L, Li LH, Wei ZF, Tong B, Jia YG, Kong $L Y$, Xia YF, Dai Y. SC-III3, a novel scopoletin derivative, induces cytotoxicity in hepatocellular cancer cells through oxidative DNA damage and ataxia telangiectasia-mutated nuclear protein kinase activation. BMC Cancer 2014; 14: 987.

10. Sun $Y$, Zhao $Y$, Wang $X$, Zhao L, Li W, Ding $Y$, Kong $L$, Guo $Q$, Lu N. Wogonoside prevents colitis-associated colorectal carcinogenesis and colon cancer progression in inflammation-related microenvironment via inhibiting NF-kappaB activation through PI3K/Akt pathway. Oncotarget 2016; 7: 34300-34315.

11. Zhang $Y$, Zhao L, Li X, Wang Y, Yao J, Wang H, Li F, Li $Z$, Guo Q. V8, a newly synthetic flavonoid, induces apoptosis through ROS-mediated ER stress pathway in hepatocellular carcinoma. Arch Toxicol 2014; 88: 97107.

12. Diaz-Moralli S, Tarrado-Castellarnau M, Miranda $A$, Cascante $M$. Targeting cell cycle regulation in cancer therapy. Pharmacol Ther 2013; 138: 255-271.

Trop J Pharm Res, October 2017; 16(10): 2312 
13. Arora H, Qureshi R, Rizvi MA, Shrivastava S, Parihar MS. Study of apoptosis-related interactions in colorectal cancer. Tumour Biol 2016; 37: 14415-14425.

14. Elias J, Dimitrio L, Clairambault J, Natalini R. The $p 53$ protein and its molecular network: modelling a missing link between DNA damage and cell fate. Biochim Biophys Acta 2014; 1844: 232-247.

15. Wang HC, Choudhary S. Reactive oxygen speciesmediated therapeutic control of bladder cancer. Nat Rev Urol 2011; 8: 608-616.

16. Zhao H, Dobrucki J, Rybak P, Traganos F, Dorota Halicka H, Darzynkiewicz Z. Induction of DNA damage signaling by oxidative stress in relation to DNA replication as detected using "click chemistry". Cytometry A 2011; 79: 897-902.
17. Pelicano H, Carney D, Huang P. ROS stress in cancer cells and therapeutic implications. Drug Resist Updat 2004; 7: 97-110.

18. Trachootham D, Alexandre J, Huang P. Targeting cancer cells by ROS-mediated mechanisms: a radical therapeutic approach? Nat Rev Drug Discov 2009; 8: 579-591.

19. Courtney KD, Corcoran RB, Engelman JA. The PIJK pathway as drug target in human cancer. J Clin Oncol 2010; 28: 1075-1083.

20. Hennessy BT, Smith DL, Ram PT, LU Y, Mills GB. Exploiting the PISK/AKT pathway for cancer drug discovery. Nat Rev Drug Discov 2005; 4: 988-1004.

21. Pandurangan AK. Potential targets for prevention of colorectal cancer: a focus on PIJK/Akt/mTOR and Wnt pathways. Asian Pac J Cancer Prev 2013; 14: 2201 2205. 